\title{
A dimensão psicopatológica da LER/DORT (Lesões por esforços repetitivos/ Distúrbios osteomusculares relacionados ao trabalho)
}

\author{
Ana Luiza Pires Batista Echeverria \\ Mário Eduardo Costa Pereira
}

As DORTs respondem por 80 a 90\% dos casos de doenças profissionais registrados na Previdência Social. Configura-se em um relevante problema do trabalho, social e econômico. Hoje a DORT já não pode mais ser explicada unicamente por processos biológicos ou fisiológicos. O artigo pretende demonstrar que a DORT é carregada de componentes subjetivos decisivos na instalação da doença e apontar para a necessidade de se estudar sua dimensão psicopatológica.

Palavras-chave: Lesões por esforços repetitivos/Distúrbios osteomusculares relacionados ao trabalho (LER/ DORT), doenças ocupacionais, psicopatologia, subjetividade 
Sísifo ousou roubar dos deuses o segredo da inteligência. Ele era um grande intelectual. Então os deuses o puniram com um castigo que consistia em levar uma grande pedra até o topo de uma montanha e chegando ao topo, a pedra rolava montanha abaixo.

Sísifo deveria pegá-la e levá-la até lá novamente e assim por toda a eternidade. Segundo a interpretação de Albert Camus, Sísifo não sofria quando subia a montanha porque, ao subir, deveria fazer um grande esforço e sua mente era tomada pelo que estava fazendo, não tendo, assim, a calma para pensar. Mas Sísifo sofria principalmente na descida. Quando a pedra caía e ele voltava para pegá-la sem fazer esforço, com toda lucidez e calma refletia sobre a punição a que tinha sido condenado, por toda a eternidadea um trabalho inútil e sem esperança. Como aquele ao qual os trabalhadores de uma linha de montagem estão condenados.

Domenico de Masi

O objetivo deste artigo é levantar hipóteses que sirvam como ponto de partida para a descrição e compreensão, segundo uma perspectiva psicanalítica, dos elementos psicopatológicos implicados na DORT/LER.

Busca-se, assim, melhor instrumentar, do ponto de vista teórico, os profissionais envolvidos com a clínica desse transtorno emocional, bem como sugerir a criação de novas formas de intervenção terapêutica junto a esses pacientes.

Inicialmente procuraremos esboçar um panorama sobre a construção histórica dos laços sociais de trabalho no contexto contemporâneo, de modo a situar o surgimento da DORT. Em seguida, a partir de um caso clínico, sustentaremos uma proposta de leitura psicanalítica dos elementos psicopatológicos que acreditamos compor a DORT.

\section{As transformações no mundo do trabalho e o sofrimento psíquico}

O mundo do trabalho vem atravessando mudanças drásticas e extremamente velozes ao longo deste último século. No Brasil, estas ocorreram antes mesmo que o trabalho tivesse atingido "um estágio de formalização e de direitos sociais equivalentes aos países desenvolvidos" (Lancman, 2004, p. 27).

Rev. Latinoam. Psicopat. Fund., São Paulo, v. 10, n. 4, p. 577-590, dez.2007 
Dentre tais transformações podemos, juntamente com Lancman, destacar: “... a introdução das novas tecnologias, a aceleração do ritmo de trabalho, as mudanças na organização do modo de produção, a necessidade de aumento de competitividade, as privatizações e fusões entre empresas que têm provocado grande impacto nas relações trabalho-emprego" (p. 2).

Será que o trabalho, no sentido histórico habitual, acabou ou está assumindo novas formas de organização? Podemos constatar a decadência de um certo modelo de trabalho, em que se idealizava um emprego estável e uma carreira linear e progressiva que culminava na aposentadoria: este é um modelo em extinção. "A flexibilização dos contratos de trabalho favoreceu a criação de formas de inserção mais instáveis" no mercado "tais como: trabalho informal, terceirização de serviços, oferta de trabalho autônomo, postos de trabalho temporários, subcontratos e terceirização" (p. 26).

As condições de trabalho vêm se deteriorando e o desemprego se alastrando há duas décadas e são conseqüências das transformações atravessadas pelo país. A abertura comercial iniciada nos anos 1990 obrigou as instituições a se modernizarem para que pudessem competir no mercado externo. Como decorrência dessa transição houve um aumento considerável de demissões. "Estima-se hoje que metade dos trabalhadores, no Brasil, trabalhe no setor informal e que o índice de desemprego seja de 13\%” (Folha de S. Paulo, 27 jun 2003).

Aqueles que ainda estão empregados também serão atingidos por essa nova lógica de restrição de oportunidades. Para se manterem empregados cedem "a perdas nos direitos trabalhistas e previdenciários, bem como dos mecanismos de proteção e fiscalização em relação à saúde, expondo-se mais aos riscos de adoecimentos e de acidentes" (Lancman, 2004, p. 5). Sem poder algum de negociação, aquele que busca uma colocação profissional acaba por ter que escolher entre um mau trabalho ou trabalho nenhum.

A descrição desse quadro é importante para que possamos enxergar o sofrimento subjetivo vivido por aqueles que convivem em um mundo onde já não existem mais as garantias, direitos e conquistas trabalhistas que os protegiam social e psiquicamente.

Será preciso muita luta e a criação de estratégias defensivas coletivas e individuais para que o trabalhador possa sobreviver psiquicamente a esta situação adversa, mascarando, contendo ou mesmo ocultando seus medos no trato com os riscos de todos os dias. Porém, nem sempre as defesas são eficazes e o sofrimento se agrava resultando em diversas formas de adoecimento, tais como: problemas psíquicos, estresse e afecções músculo-esqueléticas. “As LER/DORTs, além dos transtornos psíquicos, são hoje as principais causas de afastamento no trabalho e de aposentadorias precoces, com forte impacto nas contas da Previdência” (Lancman, 2004, p. 27). 


\section{DORT/LER, uma doença intrigante}

Podemos definir a DORT como um conjunto de doenças que atinge principalmente os membros superiores, dentre as quais as mais comuns são: a tenossinovite, a tendinite e a epicondilite.

Os números da LER são assustadores: cerca de 310 mil trabalhadores de São Paulo sofrem desse transtorno. Essa cifra equivale a $6 \%$ de todos os trabalhadores dessa cidade, conforme dados baseados em pesquisa publicada pelo Datafolha em 7/10/2001, e na qual foram entrevistados 1072 trabalhadores com mais de 16 anos, de todos os ramos de atividade.

O Governo brasileiro gasta, anualmente, com as doenças relacionadas ao trabalho e com os acidentes, cerca de 20 bilhões de reais e as empresas aproximadamente 12,5 bilhões. As LER respondem por 80 a $90 \%$ dos casos de doenças profissionais registrados na Previdência Social, nos últimos anos, e são as principais responsáveis pelo aumento significativo na incidência destas doenças verificado no país a partir de 1993. (O’Neill, 2001, p. 9).

Esta análise - feita pelo economista José Pastore - é retomada por O’Neill que, complementando os dados, mostra que as empresas despendem, no primeiro ano, em torno de 89 mil reais para cada trabalhador afastado por DORT.

Configura-se, assim, um relevante problema do trabalho, social, econômico e de saúde pública.

O que estaria acontecendo com esse trabalhadores? Trata-se de um adoecimento em massa e a análise do trabalho em categorias profissionais específicas nos mostra que "o aumento da cadência, a aceleração dos tempos e a exigência de desempenhos produtivos de rendimento crescente - herança de um taylorismo hoje globalizado - conduzem a descompensações rápidas que se desencadeiam como uma epidemia” (Déjours, 1992, p. 120).

Segundo Déjours, o momento do adoecimento pode ser explicado pela organização do trabalho na época contemporânea, porém a forma e o conteúdo só encontram explicação na estrutura da personalidade do sujeito. Em entrevista a Volich (2001) esse autor diz que, "essa Lesão por Esforços Repetitivos ou LER, não pode ser explicada unicamente por processos biológicos ou fisiológicos existe no centro disso uma verdadeira doença mental” (2001, p. 159).

Os pacientes acometidos de DORT quando procuram acompanhamento psicoterápico apresentam-se emocionalmente bastante prejudicados, em um estado de estagnação mental e embotamento tamanho que mal conseguem levar adiante um diálogo. O luto pela perda do trabalho que estão tentando encaminhar parece sugar sua energia mental de tal forma que resta uma pobreza representativa e uma imobilidade psíquica, acompanhada de muita dor física. 
A precariedade do mundo interno e das representações desses sujeitos acometidos de DORT/LER será melhor explorada a seguir.

\section{A dimensão psicopatológica da DORT/LER: o caso Sílvia}

Através de um caso clínico representativo desta psicopatologia, que chamaremos aqui o caso Sílvia, tentaremos ilustrar como foi tomando forma a idéia de uma pesquisa exploratória sobre as contribuições da psicanálise para o estudo de pacientes acometidos de LER/DORT.

Sílvia, quando chegou ao consultório pela primeira vez, apresentava uma certa facilidade de verbalização, porém sua fala era vazia, oca, presa nos elementos concretos de sua rotina e dos cálculos que fazia. Sua capacidade de fazer contas era intrigante. Quando se encontrava em conflito costumava fazer uma análise minuciosa dos gastos semanais no sentido de afirmar para si mesma que não havia desperdiçado dinheiro. Esta estranha contabilidade foi a primeira forma de tentar falar de afetos que não conseguia nomear. É importante dizer que inicialmente ela só chorava, apresentava uma angústia difusa e abordava nas sessões os temas da perda do trabalho, da perda dos movimentos dos braços, lutos que a vida lhe havia imposto, com os quais não conseguia lidar. Sua existência parecia aniquilada. Com a perda do trabalho havia perdido sua identidade profissional: já não era mais a Sílvia funcionária exemplar do banco, que tinha "rodinha" nos dedos, campeã de toques datilográficos quase todos os meses.

Sílvia era a filha caçula de uma família de sete filhos, o pai era negro e a mãe descendente de italianos. Lembra que de pequena era muito apegada à mãe, andava sempre "grudada" nela. Traz uma foto sua de quando era criança para que eu veja o quanto era feia: "Melhorei muito de lá pra cá”. Designa-se como "lombriguenta", sentia muita vontade das coisas; se via um doce queria experimentar, e tamanho era o seu desejo e a sua urgência (chegava a adoecer e ficar com febre quando passava vontade), que a mãe precisava pedir, para a vizinha ou quem quer que fosse, um pedacinho para ela.

O pai era um alfaiate conhecido na cidade, costurava para uma loja de renome. Às filhas cabia ajudar o pai nos arremates de todas as costuras a que ele dava andamento. Viviam em torno do pai ouvindo rádio e arrematando costura durante todo o dia.

Sílvia diz que seu pai já teve seus dias de glória na família, mas sempre foi muito medroso para fazer negócios e com o tempo a mãe passou a acusá-lo disso e a desqualificá-lo. Uma coisa bastante significativa neste caso é que todas as vezes em que ia à missa, Sílvia chorava ao rezar o Pai Nosso. Sílvia apresentava 
muitas das características com as quais descrevia seu pai: é emotiva, sensível e também “medrosa”.

Com o tempo, aquela menina que recebia “croques na cabeça” por não ter arrematado direito o serviço, percebendo que não tinha jeito para cuidar da casa e nem arrematar as costuras, passou a procurar trabalho. Foi assim que ela arrumou seu primeiro emprego, já como digitadora, numa empresa que processava dados para os bancos. Então, achou que no trabalho ela era "alguém" e passou a trazer dinheiro para casa. Tudo o que ganhava entregava à família; comprou móveis para mãe, bem como fez uma série de melhorias na casa.

Havia em Sílvia um profundo sentimento de menos-valia ("eu não presto para nada”) que temporariamente foi amenizado no trabalho. Em casa sempre foi desqualificada pela mãe que privilegiava a irmã. Segundo Sílvia, a mãe lhe dizia que ela "não sabia fazer uma faxina decente; a irmã mais velha é que sabia".

Sílvia procura incessantemente o reconhecimento materno, o que provoca angústia e a busca contínua de uma manifestação de afeto que nunca vinha: "Até hoje, ela nunca reconheceu nada do que fiz e faço por ela”.

O início do seu adoecimento foi marcado por um período de afastamento da mãe. Segundo seu relato, as dores começaram depois do nascimento de sua filha, em 1990 - nessa época eram dores nas costas, na região cervical. Havia acontecido uma ruptura com a sua família provocada pela não aceitação, por parte da mãe, de seu casamento. Quando a filha nasceu, Sílvia encontrava-se bastante fragilizada e tentou retomar o contato. Quando conheceu a neta disse que esta “não vingaria”. Sílvia conta esse episódio com muita dor. É como se precisasse desesperadamente do olhar de reconhecimento da mãe, de seu apoio para tornarse mãe. Com a negativa, acontece o início de seu adoecimento.

Após a explanação do caso clínico, sustentaremos uma proposta de leitura psicanalítica dos elementos psicopatológicos que acreditamos compor a DORT.

\section{DORT/LER: somatização ou conversão?}

Existe certa polêmica sobre a DORT, pois alguns autores, como Almeida (Codo e Almeida, 1995), acreditam que sua dimensão psicopatológica seja composta de uma estrutura neurótica histérica com conversões, cujas características descritas por ela são:

... necessidade de ultrapassar limites; necessidade de reconhecimento e necessidade de encobrir algum erro do passado; insatisfação pessoal; preocupação constante com a produção buscando sempre a maior quantidade com a melhor qualidade; inadmissão do sentimento de impotência (qualquer 
dificuldade encontrada é sempre um golpe na imagem que ele faz de si mesmo). (p. 33)

Segundo Freud (1893), na histeria os sintomas têm um valor simbólico e seguem uma anatomia puramente imaginária. Em suas palavras, “... nas suas paralisias e em outras manifestações, a histeria se comporta como se a anatomia não existisse, ou como se não tivesse conhecimento desta” (p. 212). Um recorte do corpo é afetado por uma paralisia ou por um sintoma somático qualquer que não coincide em nada com os trajetos da anatomia nervosa ou da anatomia em geral. "Por exemplo, afeta um braço, exclusivamente, sem que possamos encontrar vestígio seu na perna ou na face” (p. 208).

De acordo com McDougall (1996), “... o sintoma histérico clássico se manifesta por uma disfunção corporal, quando uma das partes do corpo tornase o suporte de uma significação simbólica inconsciente” (p. 18). A somatização psicossomática, por sua vez, acontece como um “'salto” da mente no corpo” (p. 18), resultante de elementos recalcados no inconsciente que, estando num nível pré-verbal, não chegaram a ser codificados pela linguagem. "Nas afecções psicossomáticas, o dano físico é bem real, e sua descrição, durante uma análise, não revela à primeira vista qualquer conflito neurótico ou psicótico” (p. 22). As somatizações envolvem aparelhos fisiológicos que constituem uma unidade funcional e não elegem este ou aquele pequeno ponto por seu valor simbólico. Os sintomas são fixos e enumeráveis, relativamente estereotipados. Na conversão histérica os sintomas podem migrar de uma região a outra e assumem um valor inteiramente individual.

O que observamos nos pacientes portadores de DORT é que há um conjunto orgânico funcional envolvido na doença: são tendões, nervos, músculos e outras estruturas dos membros superiores, pescoço e dorso. As doenças não migram de um ponto a outro, é sempre o mesmo grupo de órgãos envolvidos.

No caso Sílvia, há um conjunto orgânico funcional envolvido na doença. Ela apresentava, no membro superior direito: no punho - contratura do extensor dos quirodactilos; no cotovelo - áreas de diminuição da ecogenicidade das estruturas que aportam ao epicôndilo lateral (epicondilite lateral); no ombro - aumento da espessura e diminuição da ecogenicidade da bainha do tendão da cabeça longa do bíceps braquii (tenossinovite do tendão da cabeça longa do bíceps braquii) e irregularidade na superfície do tendão subescapular (processo inflamatório).

Em 1994 suas dores aumentaram; trabalhava com muita dor e surgiu então a bursite. Posteriormente, em 1996, a epicondilite. A região do cotovelo é esbranquiçada, segundo Sílvia, em decorrência de uma necrose por infiltração, seguida de esforço no trabalho, no mesmo dia. É importante ressaltar aqui o processo de espoliação vivido por Sílvia em seu trabalho. Lembra que trabalhava no período noturno e muitas vezes mal chegava do serviço, duas horas depois, 
eles já vinham buscá-la, pois havia faltado um funcionário. Mesmo assim, Sílvia agradecia todos os dias a oportunidade de trabalhar no banco, de dar um outro destino à sua motricidade fina, pois como já foi citado acima, a família toda se dedicava a arrematar as costuras do pai que era alfaiate.

"Eu era uma funcionária exemplar”, é uma frase que se repete nos relatos de Sílvia. Ela conta que digitava apenas com dois dedos e era tão rápida que diziam "que tinha rodinha nos dedos", sempre ficava na lista dos campeões de toques por mês. Porém, sentia que despendia um esforço enorme para digitar, diferentemente da leveza com que o irmão e o colega digitavam.

A rigidez apresentada por esses pacientes é descrita por Almeida como "perfeccionismo e inadmissão de falhas" (Codo e Almeida, 1995, p. 33). Parece haver um Ideal do Ego extremamente rígido, operando o tempo todo, que pode ter contribuído para o adoecimento dessas pessoas. O Ideal de Ego tem a função de “... velar pela satisfação narcísica do eu” (...) Todavia quando se torna severamente crítico, abandona o papel de anjo da guarda para se converter em assoladoramente demoníaco e se transforma em tenaz inimigo da segurança egóica. (...) Buraco negro no narcisismo", que inaugura a divisão do sujeito contra si mesmo (Gerez-Ambertín, 2003, p. 59).

Como já dissemos anteriormente, Sílvia apresentava no início do tratamento uma angústia difusa. Essa angústia, ao longo do processo analítico, passou a assumir a forma de algumas fobias (esboço inicial de representação do conflito vivido por ela, saindo da pobreza simbólica): medo de subir escadas e de elevador. Houve uma sessão intensa em que ela dizia de seus medos e falava para si mesma: "Que droga de mulher eu sou que tem medo de tudo". Começou a relatar seus sonhos; dentre eles havia um sonho recorrente que a aterrorizava: estava presa em algum lugar, parecia um caixão e tentava desesperadamente sair dali.

Com o andar do tratamento, através da montagem de um genograma, Sílvia chega à conclusão de que sua mãe discrimina os filhos pela cor. Conforme íamos distribuindo os filhos pelo desenho, ela ia apontando os filhos rejeitados pela mãe: eram todos mais escuros, e os claros, como a mãe, eram considerados e reconhecidos. Sílvia se vê e se descreve como mais escura que a irmã. Descreve que muitas vezes quando chega à casa da mãe, a mesma diz que seu vestido está sujo, que Sílvia não o lavou direito. Relata que outro dia ofereceu o braço à mãe para apoiá-la ao caminhar, pois esta havia caído e batido o cóccix. A mãe segurou "só um pouquinho" e já largou. Diz (com ódio) ter vontade de perguntar: "Dona Ana (o nome da mãe), qual é o problema que não pode segurar o meu braço?”

Esse episódio abriu um caminho para Sílvia começar a falar de seu ódio da mãe pelo não reconhecimento do afeto que dedicava a ela; do desejo que lhe abate de tempos em tempos de que ela morra; do quanto se sente pouco investida por ela.

No entanto, a figura da mãe permanece idealizada, inacessível; ela alimenta internamente esta mãe idolatrada. A impossibilidade de ter junto à mãe o que nunca 
foi possível, desemboca numa compulsão, pois por mais que ela ofereça à mãe o seu afeto, os seus cuidados, eles nunca são suficientes. Parece não haver abertura para que o pai entre na vida de Sílvia, embora ela reclame sempre que “falta um terceiro: já arrumei até um cachorro, mas não deu certo".

Nesse sentido, tudo o que Sílvia conquista vai para este outro, o salário era entregue todo à mãe. Essa relação de tentar ser tudo para o outro, Sílvia vai repetir no trabalho e nos faz lembrar os procedimentos autocalmantes que,

... visando encobrir a tensão dolorosa e o desamparo, buscam, paradoxalmente, restituir a calma por meio da busca repetitiva da excitação. Eles são constituídos por comportamentos motores ou perceptivos que podem incluir o sofrimento psíquico e a busca de mutilações físicas. Mediante a repetição, esses comportamentos conseguem por um tempo propiciar a calma, mas não a satisfação, ... eles não propiciam uma realização alucinatória do desejo, mas sim uma realização senso-motora da necessidade. Cria-se um clima de urgência, imperativo que exige a repetição. (Volich, 2000, p. 145)

A busca de uma descarga que produza calma só ocorre porque não houve a possibilidade de introjeção da figura materna como um pára-excitação, capaz de apaziguar o terrores internos desta filha.

Ela se exaure nesse gozo masoquista que implica o esgotamento do corpo levado ao paroxismo de seu esforço, movimento que insere o desejo de ir às últimas conseqüências na tentativa de ser alguém para este outro, na luta contra o desamparo. Sair do gozo significa cair no desamparo. Neste sentido "só lhe resta o corpo desesperadamente excitado, acometido por um terrível gozo invasor, sem nome, sem lugar, sem história” (Pereira, 1999, p. 194).

Assim como o pai, também não parece ter havido abertura para que o marido entrasse na vida de Sílvia; sua relação com ele foi bastante difícil. Ele a extorquia. Quando se casaram, ele trabalhava, depois perdeu o emprego e Sílvia passou a sustentar a família. Passou, também, a trabalhar para o gozo desse outro. Em 1996 o casamento acabou e Sílvia pediu afastamento no banco por não suportar mais as dores nos braços. Na época a vida sexual de Sílvia se resumia a raras ocasiões em que se permitia obter prazer por conta própria. Depois, passou a convidar o ex-marido para dar "uma assistência” a ela. As visitas eram semanais e não duravam mais que um ou dois dias, era o máximo que podia suportar conviver com ele. A dificuldade no trato com o prazer em Sílvia é um dos aspectos deste caso que mais nos chama a atenção; o tempo todo ela está se cercando, se impedindo, se privando de tudo que lhe dá satisfação. Grande parte de sua energia é consumida na busca do afeto inatingível da mãe. Isto aparece de forma significativa nos relatos sobre as comidas, principalmente os doces, que gosta, porém não se permite comer. Ao longo do processo terapêutico digo a ela 
que não consegue sentir o gosto doce da vida. A excitação, que buscava uma espécie de descarga ilusória em sua compulsão pelo trabalho e com ela um anseio desesperado de reconhecimento, acumula-se e transforma-se em angústia e dor.

Quando Déjours dizia que no fundo dessa doença, a DORT, há um transtorno emocional, referia-se a essa trama conflitiva nos impasses do desejo que acompanha a DORT, trama psíquica essa impossível de ser representada e concebida sob fundo de perda (Menezes, 2001, p. 260), uma perda que impôs ao sujeito um luto que ele não tinha condições psíquicas de realizar.

No caso Sílvia, a perda do trabalho remete a outras perdas, a perda do afeto da mãe, objeto irremediavelmente perdido pelo abandono. Uma tensão interna autodestrutiva, movimento mortífero do Ideal de Ego a solapar Sílvia - podemos citar aqui suas conquistas, seu trabalho no banco, e o imperativo de que deve renunciar a todo prazer -, um ódio de si, como o sujeito que se volta contra si mesmo, e a constante tentativa de religar, de restaurar a unidade com o todo primordial mítico, num movimento contínuo de desdiferenciação (Freud, 1924, p. 188).

A psique encontra-se esvaziada, sem possibilidade de representação, simbolização. Essa escassez de vida psíquica empobrece, paralisa e impede o funcionamento psíquico.

Perdida a capacidade de representar, esse sujeito vê vetada para si a condição de elaborar psiquicamente seus conflitos.

À guisa de conclusão, algumas hipóteses sobre os elementos psicopatológicos que compõem os quadros de LER podem ser levantadas. Inicialmente o paciente apresenta-se num estado de pobreza representativa e estagnação mental acompanhado de incontinência emocional e angústia difusa. A propósito de sua dinâmica interna conseguimos identificar falhas narcísicas quando sugerimos falhas na introjeção materna dificultando a criação de um páraexcitação, que servisse de tranqüilizador interno a Sílvia, o que a coloca numa busca contínua de reconhecimento. Seu adoecimento, que resulta de movimentos repetitivos, transparece a luta travada consigo mesma em busca de calma, através da descarga no movimento, ao mesmo tempo em que persegue o reconhecimento do outro, em outros, a qualquer custo, na luta contra o desamparo ("no banco eu me sentia alguém”). Este movimento associado a uma rigidez que pode ser atribuída a um Ideal de Ego, algo idealizado, inacessível que o sujeito alimenta e diante do qual se mede e se diminui (sentimento de menos-valia). "É através da crítica que se mede a distância do eu ao ideal” (Gerez-Ambertín, 2003, p. 59). Esta é a pressão interna que faz com que o sujeito participe de seu adoecimento sendo implacável consigo mesmo, ao mesmo tempo em que é pressionado institucionalmente. Enquanto este "amo" idealizado é construído e alimentado, também deseja a sua morte por ser pouco investida por ela; o gozo sádico revertese contra si mesma em gozo masoquista (Gerez-Ambertín, 2006, p. 99). 
Conseqüências sobre as abordagens com pacientes acometidos de LER/DORT

A clínica de pacientes com DORT é bastante difícil. No início do contato terapêutico a simples presença do analista (suas modalidades de presença) é mais importante do que propriamente suas intervenções. É como se ele funcionasse como um estepe de pára-excitação cuja função é garantir a sobrevivência, organizar e estruturar os destinos da angústia e propiciar a reconstrução psíquica de seu paciente. Ele colocará o seu psiquismo a serviço do trabalho terapêutico. Todos os esforços que o paciente fizer no sentido de conseguir pensar alguma coisa com o terapeuta devem ser valorizados, mas é preciso ir mais além adentrando a níveis cada vez mais regressivos. Inicia-se então o trabalho interpretativo, num segundo momento do tratamento, quando as defesas do paciente serão abordadas e os conflitos elaborados psiquicamente. É como se procedêssemos uma lenta passagem da dor ao sofrimento. A psicoterapia psicanalítica realizada junto a esses pacientes tem sido uma ferramenta mais que válida para se conseguir atingir "estados de melhora”, que se refletem nos níveis psíquico e somático, propiciando uma melhora global na qualidade de vida do paciente.

Esta pretende ser nossa contribuição ao estudo deste transtorno. É importante ampliarmos nossa visão sobre a LER, essa patologia já não pode mais ser olhada apenas como um problema somático, orgânico, nem mesmo reduzida a uma leitura das questões macrossociais que, sem dúvida, compõem o problema, porém não o explicam por completo. É necessário aprofundarmos nossos conhecimentos sobre os aspectos subjetivos implicados em todo o processo de adoecimento.

\section{Referências}

Berlinck, M. T. Psicopatologia fundamental. São Paulo: Escuta, 2000.

Codo, W. e AlmeidA, M. C. C. G. (orgs.). LER: diagnóstico, tratamento e prevenção: uma abordagem interdisciplinar. Rio de Janeiro: Vozes, 1995.

Désours, C. A loucura do trabalho: estudo de psicopatologia do trabalho. São Paulo: Cortez /Oboré, 1992.

FÉDIDA, P. Depressão. São Paulo: Escuta, 1999.

Freud, S. (1893). Algumas considerações para um estudo comparativo das paralisias motoras orgânicas e histéricas. In: Edição Standard Brasileira das Obras Psicológicas Completas de Sigmund Freud. Rio de Janeiro: Imago, 1996. v. I.

(1894). Sobre os fundamentos para destacar da neurastenia uma síndrome es- 
pecífica denominada "neurose de angústia”. In: Edição Standard Brasileira das Obras Psicológicas Completas de Sigmund Freud. Rio de Janeiro: Imago, 1996. v. II.

(1914). Sobre o narcisismo: uma introdução. In: Edição Standard Brasileira das Obras Psicológicas Completas de Sigmund Freud. Rio de Janeiro: Imago, 1996. v. XIV. (1916). Os arruinados pelo êxito. In: Edição Standard Brasileira das Obras Psicológicas Completas de Sigmund Freud. Rio de Janeiro: Imago, 1996.

(1917). Luto e melancolia. In: Edição Standard Brasileira das Obras Psicológicas Completas de Sigmund Freud. Rio de Janeiro: Imago, 1996. v. XIV.

(1923). O ego e o id. In: Edição Standard Brasileira das Obras Psicológicas Completas de Sigmund Freud. Rio de Janeiro: Imago, 1996. v. XIX.

(1924). O problema econômico do masoquismo. In: Edição Standard Brasileira das Obras Psicológicas Completas de Sigmund Freud. Rio de Janeiro: Imago, 1996. v. XIX.

Gerez-Ambertín, M. As vozes do supereu. Tradução Stella Maris Chesil. São Paulo/Caxias do Sul: Cultura Editores Associados/EDUCS, 2003.

Imperativos do supereu: testemunhos clínicos. Tradução Monica Seincman. São Paulo: Escuta, 2006.

Lancman, S. Saúde mental e trabalho: repensando a ação em Terapia Ocupacional. 2004. 189p. Tese (livre-docência). Faculdade de Medicina da USP, São Paulo.

Lancman, S. e Sznelwar, L. I. (orgs.). Christophe Déjours: da psicopatologia à psicodinâmica do trabalho. Tradução Franck Soudant. Rio de Janeiro/Brasília: Fiocruz/Paralelo 15, 2004.

Laplanche, J. A angústia. São Paulo: Martins Fontes, 1987.

Laplanche, J. e Pontalis, J.-B. Vocabulário da psicanálise. São Paulo: Martins Fontes, 1986.

Maeda, K.; Horiguchi, S. e Hosokawa, M. History of the studies on occupacional cervicobrachial disorder in Japan and remaining problems. J. Human Ergol, n. 11, p. 17-29, 1982.

Marty, P. A psicossomática do adulto. Tradução Patrícia Chittoni Ramos. Porto Alegre: Artes Médicas Sul, 1993.

Masi, D. Perspectivas para o trabalho e o tempo livre. In: Lazer numa sociedade globalizada. Leisure in a globalized society. São Paulo: SESC/WLRA, 2000.

Masson, J. A correspondência completa de Sigmund Freud para Wilhelm Fliess 1887-1904. Rio de Janeiro: Imago, 1986.

McDougall, J. Teatros do corpo: o psicossoma em psicanálise. 2. ed. Tradução Pedro Henrique Bernardes Rondon. São Paulo: Martins Fontes, 1996.

Menezes, L. C. Fundamentos de uma clínica freudiana. São Paulo: Casa do Psicólogo, 2001. 
O’Neill, M. J. O desafio de vencer. São Paulo: Visão Gráfica, 2001.

Pereira, M. E. C. Pânico e desamparo: um estudo psicanalítico. São Paulo: Escuta, 1999.

Peres, U. T. (org.). Melancolia. São Paulo: Escuta, 1996.

Ribeiro, H. P. A violência do trabalho no capitalismo: o caso das lesões dos membros superiores por esforços repetitivos (L. E. R.) em trabalhadores bancários. 1997. 328 p. Tese (doutorado em Saúde Pública). Universidade de São Paulo, São Paulo.

(org.). LER: conhecimento, práticas e movimentos sociais. São Paulo: FSP-USP, SSE-SP, 1997.

A violência oculta do trabalho: as lesões por esforços repetitivos. Rio de Janeiro: Fiocruz, 1999.

Volich, R. M.; Ferraz, C. F.; Arantes, M. A. A. C. (orgs.). Psicossoma II: psicossomática psicanalítica. São Paulo: Casa do Psicólogo, 1998.

Entrevista com Christophe Déjours. Tradução Adriana Campos de Cerqueira

Leite. Revista Latinoamericana de Psicopatologia Fundamental, São Paulo, v. IV, n. 3, p. 158-163, set. 2001.

Psicossomática: de Hipócrates à psicanálise. São Paulo: Casa do Psicólogo, 2000.

\section{Resumos}

Las LERs responden por el 80 a 90\% de los casos de molestias profesionales registrados en la Seguridad Social. Son un relevante problema de trabajo, tanto social como económico. Hoy la LER, ya no puede más ser explicada únicamente por procesos biológicos o fisiológicos. El artículo se propone demostrar que la LER está cargada de componentes subjetivos decisivos para la instalación de la enfermedad y señalar también la necesidad de estudiar su dimensión psicopatológica.

Palabras claves: Lesiones por esfuerzos repetitivos/Disturbios osteo-musculares relacionados con el trabajo (LER/DORT); molestias ocupacionales; psicopatología, subjetividad

Les LATR sont à l'origine de 80 à $90 \%$ des cas de maladies professionnelles assistées par l'Assurance Maladie, ce qui en fait un problème du travail, social et économique dont on cherche les causes au-delà des processus biologiques et physiologiques. Cet article veut: démontrer que les LATR sont chargées de composantes subjectives décisives pour que la maladie s'installe; pointer le besoin d'étudier le côté psychopathologique des LATR.

Mots clés: Lésions attribuables au travail répétitif (LATR), maladies du travail, psychopathologie, subjectivité 
Repetitive Strain Injuries (RSIs) and osteo-muscular disorders are responsible for $80 \%$ to $90 \%$ of occupacional diseases reported to health care authorities. They are generally related to occupational situations and, therefore, also constitute a social and economic problem. RSIs cannot be explained only by biological or physiological processes. This article argues that RSIa have many decisive subjetive components in their emergence, and there is need for conducting studies on their psychopathological dimensions.

Key words: Repetitive strain injury (RSI), occupacional health, psycopathology, subjectivity

\section{Ana Luiza Pires Batista Echeverria}

Psicóloga e psicanalista; mestre em Psicologia Clínica pela PUC-SP; pesquisadora do Laboratório de Psicopatologia Fundamental da Unicamp (Campinas, SP, Brasil).

Av. Washington Luiz, 2491/ 1103

19023-450 Presidente Prudente, SP, Brasil

Fone: (18) 3223-4369 ou (18) 3222-8353

e-mail: analuizab@uol.com.br

\section{Mário Eduardo Costa Pereira}

Psiquiatra, psicanalista e professor do Depto. de Psicologia Médica e Psiquiatria Unicamp (Campinas, SP, Brasil); doutor em Psicopatologia Fundamental e Psicanálise pela Universidade Paris 7; diretor do Laboratório de Psicopatologia Fundamental da Unicamp; professor do Departamento de Psicanálise do Instituto Sedes Sapientiae (São Paulo, SP, Brasil); membro da Associação Universitária de Pesquisa em Psicopatologia Fundamental (São Paulo, SP, Brasil); autor dos livros Pânico e desamparo (São Paulo: Escuta, 1999) e Psicopatologia dos ataques de pânico (São Paulo: Escuta, 2003).

Rua Carolina Prado Penteado, 725 - Nova Campinas

13092-470 Campinas, SP, Brasil

Fone: (19) 3254-5064 / 3289-4819 (Unicamp)

e-mail: marioecpereira@uol.com.br 